\title{
The effect of growth rate on pyrazinamide activity in Mycobacterium tuberculosis - insights for early bactericidal activity?
}

Steven T. Pullan ${ }^{1}$, Jon C. Allnutt ${ }^{1}$, Rebecca Devine ${ }^{2}$, Kim A. Hatch ${ }^{1 \wedge}$, Rose E. Jeeves ${ }^{1}$, Charlotte L. Hendon-Dunn ${ }^{1}$, Philip D. Marsh ${ }^{1}$ and Joanna Bacon ${ }^{1 *}$

\begin{abstract}
Background: Pyrazinamide (PZA) plays an essential part in the shortened six-month tuberculosis (TB) treatment course due to its activity against slow-growing and non-replicating organisms. We tested whether PZA preferentially targets slow growing cells of Mycobacterium tuberculosis that could be representative of bacteria that remain after the initial kill with isoniazid (INH), by observing the response of either slow growing or fast growing bacilli to differing concentrations of PZA.

Methods: M. tuberculosis H37Rv was grown in continuous culture at either a constant fast growth rate (Mean Generation Time (MGT) of $23.1 \mathrm{~h}$ ) or slow growth rate (69.3 h MGT) at a controlled dissolved oxygen tension of $10 \%$ and a controlled acidity at pH $6.3 \pm 0.1$. Cultures were exposed to step-wise increases in the concentration of PZA (25 to $500 \mathrm{gmml}^{-1}$ ) every two MGTs, and bacterial survival was measured. PZA-induced global gene expression was explored for each increase in PZA-concentration, using DNA microarray.

Results: At a constant pH 6.3, actively dividing mycobacteria were susceptible to PZA, with similar responses to increasing concentrations of PZA at both growth rates. Three distinct phases of drug response could be distingished for both slow growing (69.3 h MGT) and fast growing (23.1 h MGT) bacilli. A bacteriostatic phase at a low concentration of PZA was followed by a recovery period in which the culture adapted to the presence of PZA and bacteria were actively dividing in steady-state. In contrast, there was a rapid loss of viability at bactericidal concentrations. There was a notable delay in the onset of the recovery period in quickly dividing cells compared with those dividing more slowly. Fast growers and slow growers adapted to PZA-exposure via very similar mechanisms; through reduced gene expression of tRNA, 50S, and 30S ribosomal proteins.

Conclusions: PZA had an equivalent level of activity against fast growing and slow growing M. tuberculosis. At both growth rates drug-tolerance to sub-lethal concentrations may have been due to reduced expression of tRNA, 50S, and 30S ribosomal proteins. The findings from this study show that PZA has utility against more than one phenotypic sub-population of bacilli and could be re-assessed for its early bactericidal activity, in combination with other drugs, during TB treatment.
\end{abstract}

Keywords: Pyrazinamide, Chemostats, Growth rate, Gene expression, trans-translation, Mycobacterium tuberculosis

\footnotetext{
* Correspondence: Joanna.bacon@phe.gov.uk

Deceased

${ }^{1}$ Public Health England, National Infection Service, Porton Down, Salisbury,

Wiltshire SP4 0JG, UK

Full list of author information is available at the end of the article
} 


\section{Background}

An important aim for improving TB treatment is to shorten the period of antibiotic therapy without increasing relapse rates or encouraging the development of antibiotic-resistant strains. Pyrazinamide (PZA) is a key component of front-line chemotherapy against Mycobacterium tuberculosis (M. tuberculosis). It is thought to play an essential role in the shortened 6-month treatment course $[1,2]$ due to its ability to act upon the slowgrowing drug-tolerant organisms or antibiotic resistant organisms that emerge following treatment with the other front-line drugs, isoniazid (INH) and rifampicin.

In vitro, PZA is still far less potent than in vivo [3] and its activity against actively growing bacteria in buffered growth media has been found to be extremely low, but increases against stationary phase bacteria either under acidic conditions or if the expression of PZAactivating enzyme, PncA, is artificially increased [4]. Previously, Zhang et al., [5] exposed 4-day and 3-month old cultures to PZA for 3 days and found that the 4-day old cultures were four-fold less susceptible to PZA than the stationary phase cultures. $\mathrm{Hu}$ et al., [6] also demonstrated that 100-day old static cultures were more susceptible to PZA than 4-day and 30-day old cultures. Our aim was to determine the direct impact of growth rate on the activity of PZA (in a controlled system where the $\mathrm{pH}$ is fixed) and ascertain whether growth rate impacts the PZA concentration at which the antibiotic is bacteriostatic or bactericidal against M. tuberculosis. We observed populations of either slow growing (constant $69.3 \mathrm{~h}$ mean generation time) or fast growing bacilli (constant $23.1 \mathrm{~h}$ mean generation time) in their response to the effects of PZA exposure, using controlled and defined growth in chemostats [7, 8].

In vivo, PZA is thought to have a sterilising effect against tubercle bacilli in inflammatory lung lesions, where the $\mathrm{pH}$ is acidic $(\mathrm{pH} 5.5-\mathrm{pH}$ 6.0) [9]. During in vitro studies of PZA activity, the acidity of the growth medium is difficult to control in batch culture and acidified medium is necessary for the susceptibility testing of PZA against $M$. tuberculosis. The optimal $\mathrm{pH}$ for the activity of PZA in vitro is pH 5.6 [5]. However, previously it has been shown that $M$. tuberculosis would not grow below pH 5.8 in a hollow fibre model [10], indicating that non-dividing cells are always likely to be the target organism in every PZA susceptibility assay that uses $\mathrm{pH}$ 5.6. Previously, we observed that fast growing cells in continuous culture washed out over a period of a few days after the $\mathrm{pH}$ was reduced to a controlled acidity level of $\mathrm{pH} 6.0$, the optical density dropped from $2.0_{540 \mathrm{~nm}}$ down to $0.2_{540 \mathrm{~nm}}$ within $48 \mathrm{~h}$ [11]. The lowest acidity level that M. tuberculosis could be maintained at in steady-state growth and at a mean generation time of $23.1 \mathrm{~h}$, was $\mathrm{pH} 6.2$ in chemostat culture. Consequently, a similar $\mathrm{pH}$ was used in the current studies to enable $M$. tuberculosis to be grown under controlled environmental conditions in a chemostat at either constant slow or fast growth rates.

The major advantage of continuous culture is that it allows the growth-rate, $\mathrm{pH}$, and oxygen tension to be accurately controlled, and single parameters to be varied independently of each other $[7,8,12,13]$. Using this approach it was possible to observe the effect of different and controlled growth-rates upon PZA activity in vitro, under defined growth conditions, and at controlled oxygen tension and acidity levels. As shown previously [8], such precise control over environmental conditions is ideal for observing transcriptional responses of $M$. tuberculosis to PZA exposure when grown at different rates. A better understanding of the phenotype of the populations that PZA targets, the in vivo conditions under which it is active, and the mode of action of the drug, will enable us to develop improved assays for testing combinations of antibiotics that include PZA.

\section{Methods}

Strains, media and antibiotic

M. tuberculosis strain H37Rv (NCTC 7416) was used in all experiments. Stock cultures were routinely propagated on Middlebrook $7 \mathrm{H} 10+\mathrm{OADC}$ agar plates at $37{ }^{\circ} \mathrm{C}$ for 3 weeks. Chemostat cultures were grown in CAMR Mycobacterium medium (CMM Mod2) [14]. PZA was purchased from Sigma (P7136) and working stocks of 10 $\mathrm{mgml}^{-1}$ were prepared in water and frozen at $-20{ }^{\circ} \mathrm{C}$.

\section{Mycobacterial culture at different growth rates, and exposure to PZA}

M. tuberculosis (strain H37Rv) was grown in chemostats under controlled conditions as described previously [8] in CMM Mod2 [14], (which contained glycerol as the limiting nutrient), in a culture volume of $500 \mathrm{ml}$. Two independent continuous cultures were performed at two different growth rates to give a total of four cultures. Mean generation times (MGT) of either $23.1 \mathrm{~h}$ (fast growth) or $69.3 \mathrm{~h}$ (slow growth) were achieved by manipulating the dilution rates of the culture medium to $0.03 \mathrm{~h}^{-1}$ or $0.01 \mathrm{~h}^{-1}$, respectively. Steady-state cultures were established under defined and controlled conditions at $\mathrm{pH} 6.3$, at a temperature of $37{ }^{\circ} \mathrm{C}$ and at a dissolved oxygen tension of $10 \%[8,12] . \mathrm{pH}$ control was not imposed intially and was commenced when the culture optical density $\left(\mathrm{OD}_{540 \mathrm{~nm}}\right)$ rose above 2.0. Once $\mathrm{pH}$ control was initiated, $1 \mathrm{M} \mathrm{HCl}$ was added automatically in response to a $\mathrm{pH}$ reading higher than the desired setpoint. The $\mathrm{pH}$ was monitored constantly by an in situ probe (Broadley James). Once the culture density reached the level required, the $\mathrm{pH}$ setpoint was gradually lowered by $0.1 \mathrm{pH}$ units per MGT, until pH 6.3 was reached. All cultures were controlled at $\mathrm{pH} 6.3$ by the 
addition of $1 \mathrm{M} \mathrm{HCL}$, in a steady-state, as defined by turbidity and cell viability, for a minimum of 5 MGT prior to the onset of PZA-addition [11]. PZA was added through the sample port, the medium line was simultaneously drained, and the supply was switched over to medium containing PZA at the appropriate drug concentration. The antibiotic was added to the culture vessels in step-wise increases in the concentration of PZA (25 to $500 \mu \mathrm{gml}^{-1}$ ) every 2 MGTs.

\section{Viability assays}

The viabliity of cultures were assessed by preparing decimal dilution series of culture samples in triplicate using sterile phosphate buffered saline as the diluent and plating $100 \mu \mathrm{L}$ aliquots of each dilution onto Middlebrook $7 \mathrm{H} 10+\mathrm{OADC}$ plates, in triplicate. The plates were incubated at $37{ }^{\circ} \mathrm{C}$ for 4 weeks before colony forming units $\left(\mathrm{cfuml}^{-1}\right)$ were enumerated.

\section{RNA extraction}

For each time-point, $20 \mathrm{ml}$ of culture were harvested for RNA extraction. Extractions and DNase digestion were performed as described previously $[8,12]$. Samples were added to 4 volumes of guanidine thiocyanate (GTC) lysis solution (5 M GTC; 5 \% lauryl sarcosine; $25 \mathrm{mM}$ Trisodium citrate; $0.5 \%$ Tween 80 ) and incubated at room temperature for $1 \mathrm{~h}$. The sample mixture was centrifuged for $15 \mathrm{~min}$ at $1935 \times \mathrm{g}$ and the supernatant discarded. The pellets were re-suspended in $1.2 \mathrm{ml}$ of Trizol (Invitrogen 15596018) and mixed thoroughly. The sample was transferred to a $2 \mathrm{ml}$ tube containing $0.5 \mathrm{ml}$ of $0.1 \mathrm{~mm}$ silica beads (Fisher Scientific MBR-247-105B) and lysed using a reciprocal shaker (FastPrep FP120) for $45 \mathrm{~s}$ at a speed of 6.5. The supernatant was transferred into a tube containing $240 \mu \mathrm{l}$ of chloroform and shaken vigorously for $20 \mathrm{~s}$. This solution was centrifuged at $2415 \times \mathrm{g}$ for $10 \mathrm{~min}$. The aqueous phase was removed and added to $600 \mu \mathrm{l}$ chloroform, shaken vigorously for $20 \mathrm{~s}$ and centrifuged for $10 \mathrm{~min}$ at $2415 \times \mathrm{g}$; this process was then repeated. Following the second chloroform precipitation, the aqueous phase was added to $600 \mu \mathrm{l}$ isopropanol plus $60 \mu \mathrm{l}$ sodium acetate (Sigma Aldrich S7899) and frozen at $-70{ }^{\circ} \mathrm{C}$ overnight. Total RNA was isolated from the extractions using the mirVana ${ }^{\text {tax }}$ miRNA Isolation kit (Agilent AM1561) and DNase I-treated using the DNA-fre ${ }^{\mathrm{Tm}}$ kit (Ambion $^{\circ}$ AM1906) as per the manufacturer's instructions. RNA was quantified using a nanodrop 3000 and the quality assessed on an Agilent 2100 bioanalyzer (Agilent Technologies, CA, USA with an Agilent RNA 6000 Nano Kit (Agilent, 5067-1511).

\section{RNA labelling}

RNA was labelled using the Kreatech ULS ${ }^{\mathrm{rm}}$ Fluorescent Labeling Kit for Agilent arrays (Kreatech EA-023) as described previously [8]. The labelled RNA was fragmented by adding $2 \mu \mathrm{l} 10 \times$ fragmentation buffer, incubating for $15 \mathrm{~min}$ at $70{ }^{\circ} \mathrm{C}$, then adding $2 \mu \mathrm{l}$ stop solution (Ambion ${ }^{\circ}$ AM8740). Labelled RNA $(20 \mu \mathrm{l})$ was added to $27.5 \mu \mathrm{l}$ Kreatech blocking reagent (Kreatech EA-023), $55 \mu \mathrm{l}$ of $2 \times$ Hybridisation buffer and $7.5 \mu \mathrm{l}$ of molecular grade water. Arrays were hybridised overnight at $65{ }^{\circ} \mathrm{C}$, then washed in Gene Expression wash buffer 1 (Agilent 5188-5327) for $1 \mathrm{~min}$ at room temperature with agitation, then in Gene Expression wash buffer 2 for $1 \mathrm{~min}$ at $37{ }^{\circ} \mathrm{C}$ with agitation. Slides were scanned immediately using an Agilent Scanner.

\section{Transcriptomic analyses}

Whole genome gene expression analyses were performed. Microarray experiments were performed using a custom Agilent tiling array with 180,000 60-mer oligos evenly tiled across the $M$. tuberculosis $\mathrm{H} 37 \mathrm{Rv}$ genome. Features were extracted from the array images using Agilent Feature Extraction Software (v10.7) with local background correction. Probes were first filtered to only include those covering annotated genes. Intensity values were normalised and analysed using GeneSpring software (version 12.6 GX). Firstly, quantile normalisation was applied across the combined slow and fast growth rate datasets, followed by baseline transformation to the median of all samples and averaging of the expression level of all probes across each open reading frame. A 2way ANOVA (using a p-value cut-off of $P \leq 0.05$ and growth rate and MGT as conditions) was used to identify significantly differentially expressed genes. A further filter was applied to select genes with at least a two-fold change in gene expression between time-points of interest. Gene lists derived from all pairwise comparisons can be found in the Additional file 1. Raw data are deposited at ArrayExpress [15] under the accession number EMTAB-4093.

\section{Results \& discussion \\ The effect of growth rate on the sensitivity of $M$. tuberculosis to PZA}

M. tuberculosis cultured at a fast growth rate showed a similar response to increasing concentrations of PZA as slow growing bacilli. Duplicate cultures at either a fast growth rate (MGT of $23.1 \mathrm{~h}$ ) or slow growth rate (MGT of $69.3 \mathrm{~h}$ ) achieved a steady state in which the total viable cell numbers remained constant at $1 \times 10^{8} \mathrm{cfuml}^{-1}$ and $7 \times 10^{7} \mathrm{cfuml}^{-1}$, respectively, for a minimum of 5 MGT, at a controlled pH of 6.3 (Fig. 1).

The cultures were exposed to sequential increases in the concentration of PZA in a step-wise manner every 2 MGTs and bacterial survival was measured. The levels of

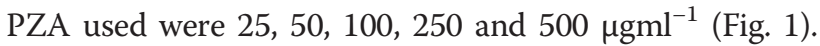
The washout rate of the chemostat (the theoretical rate at 

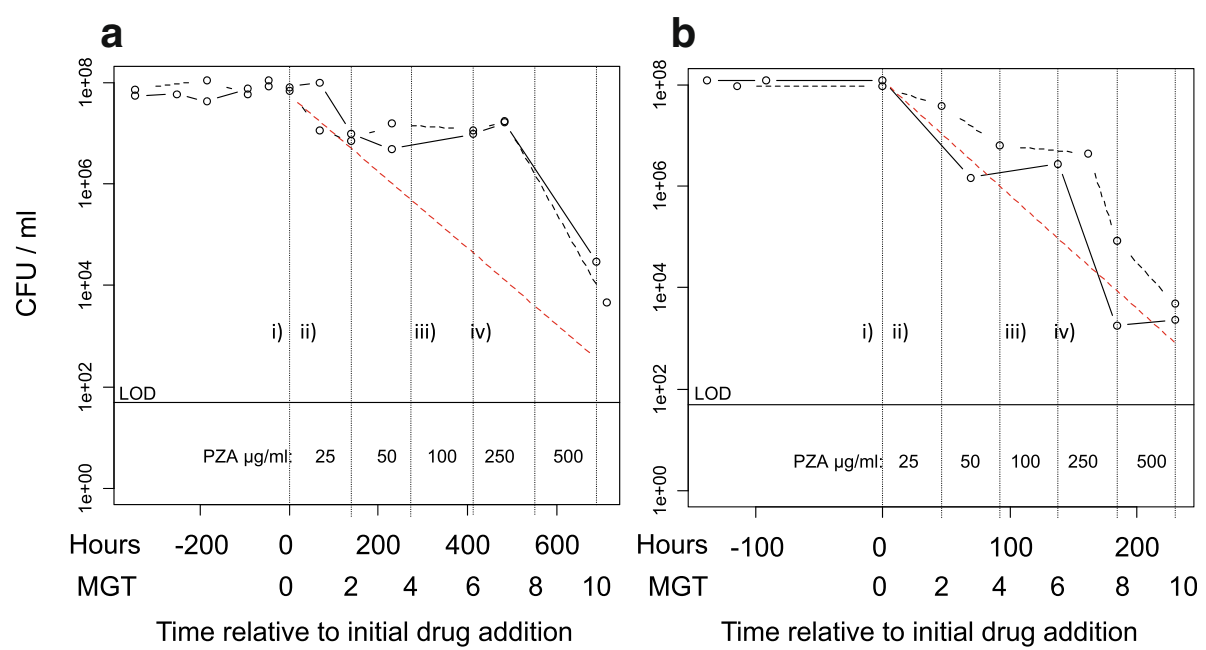

Fig. 1 The viability of $M$. tuberculosis H37Rv at either a fast growth rate or a slow growth rate in response to PZA exposure. Viability of Mycobacterium tuberculosis H37Rv growing at either a slow growth rate (69.3 h mean generation time (MGT); Panel a or a fast growth rate (23.1 h MGT; Panel $\mathbf{b}$ The cultures were exposed to sequential increases in the concentration of PZA in a step-wise manner every 2 MGTs and bacterial survival was measured. The levels of PZA used were 25, 50, 100, 250 and $500 \mathrm{\mu gml}^{-1}$; these concentrations are indicated on each graph between the vertical dotted lines to show each exposure period. Each growth rate was cultured in duplicate (solid and dashed black lines). The washout rate of the culture system is represented by the gradient of the dashed red lines. A reduction in bacterial number (cfuml ${ }^{-1}$ ) that followed this rate was indicative of a bacteriostatic drug effect. A more rapid rate of loss of viable cells indicated a bactericidal effect, and a less rapid rate indicates a sub-inhibitory effect. The limit of detection (LOD; defined as the level calculated from the presence of a single colony in one technical replicate) is indicated by the line labelled LOD. The time-points for which transcriptional analyses were performed are indicated as follows: i) pre-PZA phase, ii) bacteriostatic phase ( $4 \mathrm{~h}$ after the addition of $25 \mathrm{\mu gml}^{-1}$ ) iii) early recovery phase ( $4 \mathrm{~h}$ after the addition of 100 $\mu \mathrm{gml}^{-1} \mathrm{PZA}$ ) and iv) late recovery phase (2 MGT after the addition of $100 \mathrm{\mu gml}^{-1}$ PZA)

which non-dividing cells are removed from the culture by dilution) is indicated in Fig. 1 by the red dotted line. A reduction in the bacterial numbers that followed this rate was indicative of a bacteriostatic drug effect. A more rapid rate in the loss of bacteria indicated a bactericidal effect, and a less rapid rate indicates a sub-inhibitory effect.

Actively dividing mycobacteria were susceptible to PZA, and slow and fast growing bacteria were affected similarly (Fig. 1a \& b, respectively). Both fast and slow growing bacilli showed an approximately log-fold reduction in bacterial numbers following exposure to just $25 \mathrm{\mu gml}^{-1}$ PZA, which equated to an approximately $90 \%$ decrease in cfuml $^{-1}$ after 2 MGT (Fig. 1), after which time the growth rate was reestablished. The rate of intial loss of bacterial numbers from the system was of a similar magnitude to the washout rate and was indicative of a bacteriostatic drug effect and a minimum inhibitory concentration (MIC) of $\leq 25 \mu \mathrm{gmL}^{-1}$. This MIC agrees with previous findings by Gumbo et al., in 2009 [10] using the hollow fibre. Curiously, they deduced a similar MIC at a lower level of acidity of pH5.8. They also observed a lack of killing for four days post PZA-exposure.

Following the increase in PZA concentration to 50 $\mu \mathrm{gml}^{-1}$, a plateauing in cell titre occurred in the slow growth rate cultures, at $\sim 1 \times 10^{7} \mathrm{cfuml}^{-1}$ (Fig. 1a, approximately $10 \%$ of pre-antibiotic viable cell levels). The slow growers had adapted to the presence of PZA and remained in steady-state for 4 MGT through a further increase in PZA to $100 \mu^{-1} \mathrm{gml}^{-1}$. The fast growth-rate cultures continued to lose viability during exposure to $50 \mathrm{\mu gml}^{-1}$ but then followed a similar but delayed response by plateauing in their cell number between 100

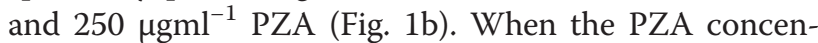
tration reached $250 \mu \mathrm{gml}^{-1}$ the bacterial numbers fell in the fast growing cultures (Fig. 1b) to approximately $1 \%$ of original pre-PZA levels after 2 MGTs, which continued following the increase to $500 \mu^{-1} \mathrm{gml}^{-1}$. It is not possible for us to say whether a PZA concentration of 250 $\mathrm{\mu gml}^{-1}$ was also bactericidal for the slow growth cultures (Panel a, Fig. 1) as after one MGT at that concentration the bacilli in these cultures were still dividing. Death of the slow growers was observed between 7MGT and 10 MGT. However, this may have been from exposure to a PZA concentration of $500 \mu \mathrm{gmL}^{-1}$ and not $250 \mu \mathrm{gmL}^{-1}$. A time-point at 8 MGT was included for the fast growers but not the slow growers. This time-point provides critical information for us to be able to conclude that bacilli at each growth rate were sterilised by the same concentration of PZA. It appears that the fast growers could have been killed at a lower PZA concentration than the slow growers but further time-courses would need to be performed to be certain of this. By the end of the PZA-exposure time-course (10 MGT), less 
than $0.1 \%$ of the original viable cell population was remaining in all cultures. The results show that high concentrations of PZA will sterilise the population irrespective of growth rate. The bactericidal response observed in our cultures was at a concentration that was much higher than observed previously in studies when the environmental $\mathrm{pH}$ was lower. The experiments described here were designed to specifically determine the effect of growth rate on PZA efficacy and therefore a higher $\mathrm{pH}$ had to be used to enable cells to continue to divide.

The mode of action of PZA was described previously by Zhang et al., in 2003 [16]. PZA, a pro-drug, is converted to pyrazinoic acid (POA) by an amidase (encoded by gene; Rv2043c, $p n c A$ ) found in the bacterial cytoplasm [17]. POA is excreted from the bacteria and then it diffuses passively back in through the cell wall as the protonated molecule (HPOA) when the $\mathrm{pH}$ of the bacterial environment is acidic. Multiple mechanisms of action have been identified for POA; it has been shown to decrease the proton motive force and ATP synthesis rates in mycobacterial membranes as well as lowering cellular ATP levels in Mycobacterium bovis BCG [18]. Further support is given to this by the observations that some weak acids and energy inhibitors work synergistically with PZA [19] and mutations in energy production and ion homeostasis pathways enhance PZA activity [20]. The reported bactericidal concentration of PZA in vitro under more acidic condtions at a $\mathrm{pH}$ of 5.6 is $50 \mu \mathrm{g} / \mathrm{ml}$ [5]. Bactericidal effects were observed between 250 and $500 \mu \mathrm{gml}^{-1} \mathrm{PZA}$ in this study for both growth rates; this reduction in effectiveness (5-fold) is in proportion with the expected fold-decrease in internal POA concentration commenserate with a less acidic external condition in our chemostat cultures ( $\mathrm{pH}$ 6.3) as calculated using the Henderson-Hasselbalch equation [5, 21]. Previously, it had been shown that the slowing of bacterial growth reduced the activity of an efflux pump, which is then inefficient at extruding HPOA from the cell, thereby leading to an accumulation of HPOA and subsequently increased bactericidal effects. In our study, we did not observe any effect of bacterial growth rate on the overall sterilising activity of PZA. This suggests that it is not growth rate per se that determines PZA activity; increased drug activity observed during stationary phase must be due to other aspects of bacterial metabolism.

PZA has no detectable early bactericidal activity (EBA) in the first 2 days of treatment [22]; monotherapy ranges from 0.04 to $0.1 \log _{10} \mathrm{cfuml}^{-1}$ day $^{-1}$ [9]. However, despite this lack of efficacy, PZA exerts an effect by shortening treatment only during the first 2 months of treatment and not beyond this. Extending the duration of treatment with PZA has no additional benefit in either humans or murine models [3, 23, 24]. Can we be sure that PZA is not exerting a profound bacteriostatic effect against actively dividing organisms during the first phase of treatment? It has always been assumed that INH clears the fast growing population during EBA leaving slow growing drug-tolerant (as opposed to genetically resistant) bacteria that need to be cleared by other drugs such as PZA. However, in a recent study we showed that both fast and slow growing cells persist through INH exposure via different growth rate-specific genotypic and phenotypic mechanisms [8]. Therefore, we cannot generalise that fast growing bacteria are sterilised during EBA and slow growing cells are sterilised later during treatment. The contribution of PZA to the clearance of fast growing bacteria during the first phase of treatment has not been fully explored but it may be having hidden and profound effects such as controlling bacterial numbers or preventing antibiotic resistance from arising. Could the activity of PZA be improved during the first phase of treatment by using it in combination with other antibiotics that boost its activity? The maximum peak level of PZA attainable in patients' blood is $30-60 \mu^{-1} \mathrm{gml}^{-1}$ which is the optimal killing concentration in vitro at $\mathrm{pH} 5.6$ [25]. More defined and reproducible in vitro systems that can test combinations of drugs, including PZA, against $M$. tuberculosis and achieve lower concentrations of PZA which deliver more potent bactericidal activity would help to shorten treatment times. Previously, Grosset et al., [26] demonstrated in mice that INH could be having antagonistic effects on the efficacy of PZA, and that there might be benefits of removing INH after the first 2 days of treatment. As PZA is a lead drug in terms of good sterilising activity, it is important to understand how other drugs have an impact on PZA efficacy and how we can rationalise the use of current drugs to optimise its activity. The postponement of PZA use after the initial bactericidal phase has been suggested [26] but this may not be beneficial given the information presented here demonstrating that PZA has a comparable level of activity against fast and slow growing cells of $M$. tuberculosis. It may be more appropriate to optimise combinations that improve the efficacy of PZA from the start of treatment. Is there a case for replacing INH with alternative antibiotics that increase the activity of PZA and do not give rise to resistance in the way that INH does? This has been demonstrated recently by a clinical trial of PZA in combination with moxifloxacin and Pretomanid (PA-824) [27], which showed superior bactericidal activity in drug-susceptible TB during 8 weeks of treatment. Results were consistent between drug-susceptible and multi-drug resistant (MDR) TB. This new regimen is ready to enter phase 3 trials in patients with drug-susceptible TB and MDR-TB, with the goal of shortening and simplifying treatment. 


\section{Transcriptional analysis}

Three distinct phases of response to PZA can be distinguished in cells growing at slow or fast growth rates (Fig. 1, panels a \& b, respectively) There was an initial loss of bacteria as PZA was added to the system at inhibitory levels (25 $\mathrm{\mu gml}^{-1}$; "bacteriostatic phase"), followed by a phase in which bacilli had adapted to the presence of PZA and were actively dividing in steady state ("recovery phase"). Finally a rapid loss of culture viability was observed once the levels of PZA became bactericidal ("bactericidal phase"). The most notable difference in the response to PZA between cells growing at the two growths rates was that the slow growing bacteria plateaued earlier in the recovery phase than the fast growers (Fig. 1). Global gene expression was analysed to see if the mechanisms of adaptation to pyrazinamde in the 'recovery phase' were different between bacilli cultured at different growth rates. RNA was extracted at time-points prior to PZA-addition ("pre-PZA phase" Fig. 1.i)), during the bacteriostatic phase ( $4 \mathrm{~h}$ after the addition of $25 \mathrm{\mu gml}^{-1}$, "bacteriostatic phase" Fig. 1.ii)), and during the recovery period ( $4 \mathrm{~h}$ after the addition of $100 \mathrm{\mu gml}^{-1}$ PZA, "early recovery phase" Fig. 1.iii), and 2 MGT after the addition of $100 \mu \mathrm{gml}^{-1} \mathrm{PZA}$, "late recovery phase" Figure.iv)). The RNA was analysed by whole genome DNA microarray and the data are deposited in ArrayExpress, accession no. E-MTAB-4093 [15]. The two time-points within the recovery phase were selected to cover the overlap in the recovery periods for the two growth rates. The $4 \mathrm{~h}$ timepoint was early on in the recovery of the fast growers and mid-recovery for slow ("early recovery" Fig. 1.iii)), whereas the time-point at 2MGT after this was at the end of the recovery period for both growth rates ("late recovery" Fig. 1.iv)). No genes were differentially expressed between the pre-PZA phase (Fig. 1.i)) and the bacteriostatic phase (Fig. 1.ii)) under slow growth using selection criteria of an Anova p-value of less than 0.05 and a minimum fold change of two. In contrast, four genes were up-regulated under fast growth between these phases: Rv2645 (uncharacterised), Rv2738c (uncharacterised), Rv3221 (biotynylated protein TB7.3), and Rv3018c (uncharacterised PPE family protein), (Additional file 1: Table S1). Following this, comparisons were made between the pre-PZA phase and the recovery phases. There were 341 differentially expressed genes in the early recovery phase (Fig. 1.iii)) compared to pre-PZA phase (Fig. 1.i)) in slow growing cells, which consisted of 115 up-regulated genes and 226 downregulated genes (Fig. 2. \& Additional file 1: Table S2). In the late-recovery phase (Fig. 1.iv)) there were 415 genes differentially expressed under slow growth, which consisted of 148 up-regulated genes and 267 downregulated genes (Fig. 2. \& Additional file 1: Table S2). There were 85 shared up-regulated genes and 204 shared down-regulated genes across the two timepoints in the recovery phase (Fig. 1 iii) and iv)) for slow growth (Fig. 2. \& Additional file 1: Table S2.). In the fastgrowing cultures there were only two differentially expressed genes in the early recovery phase (Fig. 1.iii)), both of which were up-regulated. In the late recovery phase (Fig. 1iv)), 38 genes were differentially expressed, which consisted of 10 up-regulated genes and 28 downregulated genes (Fig. 2. \& Additional file 1: Table S3).

\section{Differentially expressed genes were enriched for functions encoding Ribosomal proteins and tRNAs}

To determine whether differentialy expressed genes were significantly enriched for particular functions, functional annotation clustering reports were generated using the DAVID 6.7 bioinformatic resource [28] with Uniprot IDs

\section{Slow Growth}

(69.3h MGT)

iil) Early Recovery iv) Late Recovery

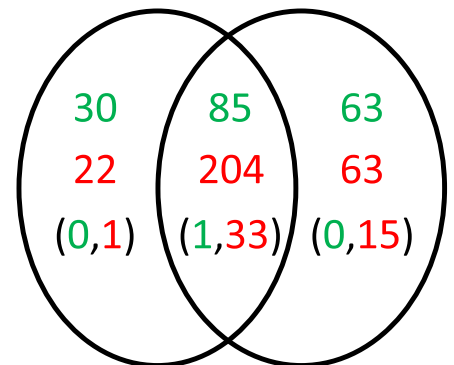

Fast Growth

(23.1h MGT)

iil) Early Recovery $\quad$ iv) Late Recovery

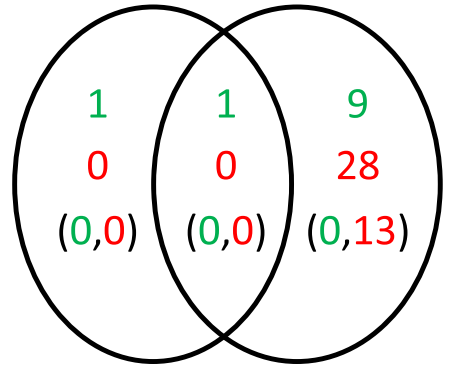

Fig. 2 Significantly differentially expressed genes during PZA-exposure. Numbers of genes up-regulated (in green) or down-regulated (in red), with a fold-change greater than two-fold and ANOVA p-value less than 0.05 , in the early recovery phases ( $4 \mathrm{~h}$ after the addition of $100 \mathrm{mgml}^{-1} \mathrm{PZA}$ ) and late recovery phases (2 mean generation times (MGT) after the addition of $100 \mathrm{mgml}^{-1}$ PZA) compared to the pre-PZA phases under fast growth rates (23.1 h MGT) and slow growth rates (69.3 h MGT). The numbers shown in brackets refer to the subset of genes in each case that encode either tRNAs or ribosomal protein components 
as the input. A Bonferroni-corrected EASE-value cutoff of 0.01 (EASE-value being an alternative name for the one-tail Fisher Exact Probability Value used to measure gene-enrichment in annotation terms, compared to proportions of these genes encoded within the genome) was employed along with a minimum gene number per category of five genes (i.e. a category cannot be considered to be enriched unless at least five genes from a function are present). The functional annotation clustering report groups similar categories of annotations together into clusters. None of the up-regulated genes were significantly enriched for any functional categories. Under slow growth, the 226 down-regulated genes in the early recovery phase and the 267 down-regulated genes in the late recovery phase (Fig. 2.) were significantly enriched in 15 categories as defined by the GO ontology database [29], the Protein Information Resource (PIR) [30], and the KEGG pathway database [31] (Table 1.). All 15 categories were clustered into a single group by DAVID, and no other categories outside the group were enriched. All categories relate to ribosomal functions. From the fast growth rate cultures, there were no significantly enriched categories in the early recovery phase, but the 31 down-regulated genes in the late recovery phase (Fig. 2.) showed significant enrichment for the same 15 ribosomal function related categories seen under slow growth conditions.
At a gene-specific level, during the early recovery phase, eight tRNA-encoding genes and 26-ribosomalprotein encoding genes were down-regulated in the slow growing cultures (Table 1, Fig. 2. brackets, Table 2.), with a single up-regulated gene encoding a ribosomal protein (Rv2442, 50s ribosomal protein L21). In contrast, no genes of this function were differentially expressed in the fast growing cultures. By late recovery under slow growth, there were 17 tRNA-encoding genes and 31 ribosomal-protein encoding genes showing significant down-regulation compared to the prePZA phase. There were also 6 tRNA-encoding genes and seven ribosomal protein encodoing genes downregulated in the fast growing bacteria in the late recovery phase (Table 3.). The delayed down-regulation seen during fast growth was co-incident with the delayed plateau in culture viability.

It is challenging to ascertain which of the PZA targets make the biggest contribution to cell death. With so many modes of action does PZA act predominantly upon the the same target and in all bacterial phenotypes under different growth conditions? Given the multiple modes of action, we were interested in which phenotypic mechanisms were employed by fast and slow growing bacilli to enable them to overcome the effects of the antibiotic and to observe any obvious growth-rate specific mechanisms. It was postulated previously that POA disrupts bacterial membrane energetics and inteferres

Table 1 DAVID Functional annotation clustering of genes that were down-regulated in M. tuberculosis exposed to PZA under different growth rates in early and late recovery

\begin{tabular}{|c|c|c|c|c|c|c|c|c|c|}
\hline \multirow[b]{3}{*}{ Annotation scheme } & \multirow[b]{3}{*}{ Annotation } & \multicolumn{4}{|c|}{ Slow growth (69.3 h MGT) } & \multicolumn{4}{|c|}{ Fast growth (23.1 h MGT) } \\
\hline & & \multicolumn{2}{|c|}{$\begin{array}{l}\text { Down-regulated } \\
\text { in early recovery }\end{array}$} & \multicolumn{2}{|c|}{$\begin{array}{l}\text { Down-regulated } \\
\text { in late recovery }\end{array}$} & \multicolumn{2}{|c|}{$\begin{array}{l}\text { Down-regulated } \\
\text { in early recovery }\end{array}$} & \multicolumn{2}{|c|}{$\begin{array}{l}\text { Down-regulated } \\
\text { in late recovery }\end{array}$} \\
\hline & & Count & $\begin{array}{l}\text { Bonferroni } \\
\text { corrected } \\
\text { EASE-value }\end{array}$ & Count & $\begin{array}{l}\text { Bonferroni } \\
\text { corrected } \\
\text { EASE-value }\end{array}$ & Count & $\begin{array}{l}\text { Bonferroni } \\
\text { corrected } \\
\text { EASE-value }\end{array}$ & Count & $\begin{array}{l}\text { Bonferroni } \\
\text { corrected } \\
\text { EASE-value }\end{array}$ \\
\hline KEGG_PATHWAY & ribosome & 25 & $4.00 \mathrm{E}-24$ & 28 & $1.70 \mathrm{E}-26$ & $\mathrm{n} / \mathrm{a}$ & $\mathrm{n} / \mathrm{a}$ & 7 & $4.20 \mathrm{E}-08$ \\
\hline GOTERM_MF_FAT & structural constituent of ribosome & 25 & $1.60 \mathrm{E}-21$ & 28 & 4.10E-25 & $\mathrm{n} / \mathrm{a}$ & n/a & 7 & 1.10E-08 \\
\hline SP_PIR_KEYWORDS & ribonucleoprotein & 25 & $3.60 \mathrm{E}-21$ & 28 & $3.40 \mathrm{E}-24$ & $\mathrm{n} / \mathrm{a}$ & $\mathrm{n} / \mathrm{a}$ & 7 & $1.90 \mathrm{E}-06$ \\
\hline GOTERM_MF_FAT & rRNA-binding & 21 & $1.00 \mathrm{E}-20$ & 23 & $2.30 \mathrm{E}-23$ & $\mathrm{n} / \mathrm{a}$ & $\mathrm{n} / \mathrm{a}$ & 4 & $1.10 \mathrm{E}-03$ \\
\hline SP_PIR_KEYWORDS & rRNA-binding & 21 & $7.80 \mathrm{E}-21$ & 23 & $4.30 \mathrm{E}-23$ & $\mathrm{n} / \mathrm{a}$ & $\mathrm{n} / \mathrm{a}$ & 4 & 8.10E-03 \\
\hline SP_PIR_KEYWORDS & ribosomal protein & 25 & $3.50 \mathrm{E}-20$ & 28 & $5.00 \mathrm{E}-23$ & $\mathrm{n} / \mathrm{a}$ & $\mathrm{n} / \mathrm{a}$ & 7 & $3.10 \mathrm{E}-06$ \\
\hline GOTERM_MF_FAT & structural molecule activity & 25 & $5.50 \mathrm{E}-20$ & 28 & $2.60 \mathrm{E}-23$ & $\mathrm{n} / \mathrm{a}$ & $\mathrm{n} / \mathrm{a}$ & 7 & $2.50 \mathrm{E}-08$ \\
\hline GOTERM_CC_FAT & ribosome & 25 & $2.50 \mathrm{E}-19$ & 28 & $1.30 \mathrm{E}-21$ & $\mathrm{n} / \mathrm{a}$ & $\mathrm{n} / \mathrm{a}$ & 7 & $9.80 \mathrm{E}-05$ \\
\hline GOTERM_CC_FAT & ribonucleoprotein complex & 25 & $8.80 \mathrm{E}-19$ & 28 & $5.60 \mathrm{E}-21$ & $\mathrm{n} / \mathrm{a}$ & $\mathrm{n} / \mathrm{a}$ & 7 & $1.30 \mathrm{E}-04$ \\
\hline GOTERM_BP_FAT & translation & 29 & $1.10 \mathrm{E}-17$ & 32 & $1.00 \mathrm{E}-19$ & $\mathrm{n} / \mathrm{a}$ & $\mathrm{n} / \mathrm{a}$ & 7 & $9.20 \mathrm{E}-06$ \\
\hline SP_PIR_KEYWORDS & RNA-binding & 22 & $7.50 \mathrm{E}-16$ & 25 & $1.50 \mathrm{E}-18$ & $\mathrm{n} / \mathrm{a}$ & n/a & 4 & $4.50 \mathrm{E}-02$ \\
\hline GOTERM_MF_FAT & RNA binding & 26 & $1.80 \mathrm{E}-14$ & 27 & $1.80 \mathrm{E}-14$ & $\mathrm{n} / \mathrm{a}$ & $\mathrm{n} / \mathrm{a}$ & 5 & $1.50 \mathrm{E}-03$ \\
\hline GOTERM_CC_FAT & ribosomal subunit & 10 & 8.60E-09 & 10 & $3.60 \mathrm{E}-08$ & $\mathrm{n} / \mathrm{a}$ & $\mathrm{n} / \mathrm{a}$ & 4 & $3.20 \mathrm{E}-03$ \\
\hline
\end{tabular}

A corrected EASE-value of 0.01 and minimum gene number per category of five was used to perform functional annotation clustering on all down-regulated genes in the early recovery phase $\left(4 \mathrm{~h}\right.$ after the addition of $\left.100 \mathrm{\mu gml}^{-1} \mathrm{PZA}\right)$ or the late recovery phase ( $2 \mathrm{MGT}^{\mathrm{after}}$ the addition of $\left.100 \mathrm{\mu gml} \mathrm{l}^{-1} \mathrm{PZA}\right)$ compared to the pre-PZA phase 
Table 2 Ribosomal and tRNA associated genes down-regulated in M. tuberculosis exposed to PZA under slow growth

\begin{tabular}{|c|c|c|c|c|}
\hline $\begin{array}{l}\text { Gene expression fold change from } \\
\text { pre-PZA to early recovery phase } \\
\left(100 \mu \mathrm{gml}^{-1} \text { for } 4 \mathrm{~h}\right)\end{array}$ & $\begin{array}{l}\text { Gene expression fold change from } \\
\text { pre-PZA to iv) late recovery phase } \\
\left(100 \mathrm{\mu gml}^{-1} \text { for } 2 \mathrm{MGT}\right)\end{array}$ & Gene name & UniProt ID & Annotation \\
\hline-4.81 & -11.22 & tRNA-Val & & tRNA-Val \\
\hline-3.23 & -10.01 & tRNA-Glu & & tRNA-Glu \\
\hline-3.99 & -9.34 & tRNA-Lys & & tRNA-Lys \\
\hline-5.13 & -8.95 & Rv0700 & P0A5X0 & $30 \mathrm{~S}$ ribosomal protein $\mathrm{S} 10$ \\
\hline-2.63 & -8.62 & tRNA-Gly & & tRNA-Gly \\
\hline-3.52 & -8.60 & tRNA-Thr & & tRNA-Thr \\
\hline-4.86 & -8.15 & tRNA-Arg & & tRNA-Arg \\
\hline-5.22 & -7.36 & Rv0704 & P95052 & 50 S ribosomal protein L2 \\
\hline-4.49 & -7.33 & tRNA-Met & & tRNA-Met \\
\hline-4.68 & -6.35 & Rv0703 & P95051 & 50 S ribosomal protein L23 \\
\hline-4.29 & -6.16 & Rv1298 & P66187 & $50 S$ ribosomal protein $\mathrm{L} 31$ \\
\hline-1.65 & -6.13 & tRNA-Leu & & tRNA-Leu \\
\hline-2.33 & -5.97 & tRNA-Ser & & tRNA-Ser \\
\hline-4.08 & -5.88 & Rv0710 & P95058 & $30 S$ ribosomal protein S17 \\
\hline-1.65 & -5.43 & tRNA-Pro & & tRNA-Pro \\
\hline-3.70 & -5.20 & Rv0705 & P0A5X4 & 30 s ribosomal protein S19 \\
\hline-1.44 & -4.83 & tRNA-Tyr & & tRNA-Tyr \\
\hline-3.56 & -4.82 & Rv0709 & P95057 & 50 S ribosomal protein L29 \\
\hline-4.32 & -4.82 & Rv0702 & P60729 & $50 S$ ribosomal protein $\llcorner 4$ \\
\hline-3.99 & -4.72 & Rv0722 & P66181 & $50 S$ ribosomal protein L30 \\
\hline-3.09 & -4.66 & Rv0701 & P60442 & $50 S$ ribosomal protein $\mathrm{L} 3$ \\
\hline-3.76 & -4.17 & Rv0716 & P62403 & $50 S$ ribosomal protein $L 5$ \\
\hline-3.32 & -3.98 & Rv0717 & P0A5X2 & 30 S ribosomal protein S14 type Z \\
\hline-3.48 & -3.79 & Rv0682 & P41196 & $30 S$ ribosomal protein $\mathrm{S} 12$ \\
\hline-3.01 & -3.69 & Rv0715 & P60627 & $50 S$ ribosomal protein L24 \\
\hline 1.03 & -3.68 & tRNA-Cys & & tRNA-Cys \\
\hline-3.45 & -3.61 & Rv1643 & P66105 & $50 S$ ribosomal protein L20 \\
\hline-2.99 & -3.56 & Rv0723 & P95071 & 50 s ribosomal protein L15 \\
\hline-1.44 & -3.38 & tRNA-Trp & & tRNA-Trp \\
\hline-2.97 & -3.32 & Rv2412 & P66505 & $30 S$ ribosomal protein S20 \\
\hline-3.07 & -3.22 & Rv0683 & P41194 & $30 \mathrm{~S}$ ribosomal protein S7 \\
\hline-4.07 & -3.05 & Rv0718 & P66625 & 30 S ribosomal protein $\mathrm{S} 8$ \\
\hline-3.13 & -3.04 & Rv1642 & P66271 & $50 S$ ribosomal protein L35 \\
\hline-2.59 & -3.02 & Rv0714 & P66069 & 50 S ribosomal protein L14 \\
\hline-2.79 & -2.92 & Rv0707 & P0A5X6 & 30 S ribosomal protein S3 \\
\hline-1.06 & -2.91 & 5S_rRNA & & ribosomal RNA \\
\hline-2.44 & -2.91 & Rv0721 & P66574 & 30 S ribosomal protein S5 \\
\hline 1.03 & -2.84 & tRNA-Asp & & tRNA-Asp \\
\hline-1.14 & -2.67 & tRNA-His & & tRNA-His \\
\hline-1.10 & -2.65 & tRNA-Phe & & tRNA-Phe \\
\hline-1.45 & -2.64 & tRNA-Ile & & tRNA-Ile \\
\hline 1.00 & -2.45 & $23 \mathrm{~S}$ rRNA & & ribosomal RNA \\
\hline-1.41 & -2.39 & Rv0640 & P66056 & 50 S ribosomal protein L11 \\
\hline
\end{tabular}


Table 2 Ribosomal and tRNA associated genes down-regulated in M. tuberculosis exposed to PZA under slow growth (Continued)

$\begin{array}{lllll}1.00 & -2.27 & \text { 16S rRNA } & & \text { Ribosomal RNA } \\ -2.01 & -2.27 & \text { Rv0720 } & \text { P66076 } & \text { 50S ribosomal protein L18 } \\ -1.84 & -2.17 & \text { Rv0719 } & \text { P66311 } & \text { 50S ribosomal protein L6 } \\ -2.15 & -2.07 & \text { Rv0055 } & \text { P69230 } & \text { 30S ribosomal protein S18 } 1 \\ -1.67 & -2.03 & \text { Rv1630 } & \text { O06147 } & \text { 30S ribosomal protein S1 } \\ -2.35 & -1.92 & \text { Rv1644 } & \text { P94978 } & \text { possible 23S rRNA methyltransferase tsnR }\end{array}$

Genes encoding tRNAs or ribosome component proteins that were down-regulated by at least two fold (with an ANOVA $p$-value of less than 0.05) in $M$. tuberculosis under slow growth in the early recovery phase ( $4 \mathrm{~h}$ after the addition of $\left.100 \mu \mathrm{gml}^{-1} \mathrm{PZA}\right)$ and/or the late recovery phase ( $2 \mathrm{MGT}$ after the addition of 100 $\mu \mathrm{gml}^{-1} \mathrm{PZA}$ ) compared to the pre-PZA phase

with energy production [16]. Stationary phase bacilli might have a lower membrane potential than actively dividing log-phase bacteria, which could explain the increased activity of PZA against stationary phase bacteria observed previously. No gene expression changes were observed for genes encoding functions related to membrane potential. Bacilli in fast and slow growth cultures may not have exhibited much difference in membrane potential explaining the similar response to PZA-exposure. Understanding the specific differences between bacterial stationary phase and slow growth might enable us to dissect out the range of activities that PZA has against bacilli in different phenotypic states. Fast growers and slow growers were adapting to PZA-exposure via very similar mechanisms. The only functions that were differentially expressed under each growth rate, that were also enriched for function using DAVID analyses, were genes encoding tRNA, $50 \mathrm{~S}$ and $30 \mathrm{~S}$ ribosomal proteins, which were down-regulated during the recovery phase. This may go some way to explaining why the populations at both growth rates were adapting and establishing new steady-states, but at a lower cell density. The maximum cell number sustainable on the available nutrient was simply less because of a reduction in level of protein that was being translated leading to a subsequent decrease in available target. Recently, Shi et al., [32] found that POA binds the ribosomal protein $\mathrm{S} 1$ (RspA), which is a vital protein for trans-translation, and inhibits the trans-translation activity required for efficient protein synthesis. Mutations in rpsA (gene Rv1630) result in PZA-resistance, and are alternative mechanisms of resistance to mutations in pncA [33-35]. Trans-translation is essential for rescuing stalled ribosomes during translation in non-replicating organisms and inhibition of this process could be one mechanisms by which PZA targets persisting organisms. Bacteria require trans-translation to respond

Table 3 Ribosomal and tRNA associated genes down-regulated in M. tuberculosis exposed to PZA under fast growth

\begin{tabular}{|c|c|c|c|c|}
\hline $\begin{array}{l}\text { Fold change from pre-PZA to } \\
\text { early recovery phase } \\
\left(100 \mathrm{\mu gml}^{-1} \text { for } 4 \mathrm{~h}\right) \\
\end{array}$ & $\begin{array}{l}\text { Fold change from pre-PZA } \\
\text { to late recovery phase } \\
\left(100 \mathrm{\mu gml}^{-1} \text { for } 2 \mathrm{MGT}\right) \\
\end{array}$ & Gene name & UniProt ID & Annotation \\
\hline 1.12 & -2.03 & tRNA-Glu & & tRNA-Glu \\
\hline-1.45 & -2.07 & Rv0704 & P95052 & $50 S$ ribosomal protein L2 \\
\hline-1.43 & -2.10 & Rv0723 & P95071 & $50 S$ ribosomal protein L15 \\
\hline-1.02 & -2.11 & tRNA-Thr & & tRNA-Thr \\
\hline-1.07 & -2.20 & tRNA-Lys & & tRNA-Lys \\
\hline-1.12 & -2.26 & tRNA-Arg & & tRNA-Arg \\
\hline-1.55 & -2.31 & Rv0703 & P95051 & $50 S$ ribosomal protein L23 \\
\hline-1.60 & -2.33 & Rv0700 & P0A5X0 & $30 S$ ribosomal protein $\mathrm{S} 10$ \\
\hline-1.51 & -2.40 & Rv0722 & P66181 & $50 S$ ribosomal protein $L 30$ \\
\hline-1.14 & -2.42 & tRNA-Val & & tRNA-Val \\
\hline-1.79 & -2.45 & Rv0709 & P95057 & $50 S$ ribosomal protein L29 \\
\hline-1.90 & -2.72 & Rv0710 & P95058 & 30 S ribosomal protein S17 \\
\hline-1.10 & -2.04 & tRNA-Met & & tRNA-Met \\
\hline
\end{tabular}

Genes encoding tRNAs or ribosome component proteins that were down-regulated by at least two fold (with an ANOVA $p$-value of less than 0.05 ) in $M$. tuberculosis under fast growth in the early recovery phase ( $4 \mathrm{~h}$ after the addition of $\left.100 \mu \mathrm{gml}^{-1} \mathrm{PZA}\right)$ and/or the late recovery phase ( $2 \mathrm{MGT}$ after the addition of 100 $\mathrm{mgml}^{-1} \mathrm{PZA}$ ) compared to the pre-PZA phase 
to stress, pathogenesis, and differentiation, which indicates that fast growing organisms also require trans-translation to overcome stress [36]. Based on this mode of action for PZA, it follows that fast-growing organisms would be targeted by PZA. Increased PZA efficacy against fast growing cells could be enabled by potentiators that create stress/ reduce metabolism, such as energy inhibitors, in fast growers [37, 38].

The recovery period co-incident with the downregulation of ribosomal protein encoding genes seen in this study might reflect a mechanism to reduce the production of toxic proteins caused by the inhibition of trans-translation [39]. Alternatively adaptation may have occurred through an increase in the mutant frequency and diversity of mutations as previously shown in the adaptation of fast and slow growing $M$. tuberculosis to INH exposure and we would expect (as shown for INH-exposure) that there would be a difference in the mutant profile between the two different growth rates. Much is understood about how M. tuberculosis adapts to PZA-exposure by the development of resistance mutations in pncA and more recently mutations have been shown in panD [20], which encodes aspartate-alpha-decarboxylase involved in the synthesis of $\beta$-alanine that is a precursor for pantothenate and co-enzyme-A biosynthesis [40] and may be yet another target for PZA.

\section{Conclusions}

PZA has an equivalent level of activity against fast growing and slow growing $M$. tuberculosis under the conditions tested here. Both populations appeared to adapt to PZA-exposure via reduced expression of tRNA, 50S, and 30S ribosomal proteins. Understanding the subtle differences between bacterial growth rate and growth phase will enable us to dissect out the range of activities that PZA has against bacilli in different phenotypic states and aid the development of drug combinations containing PZA. The contribution of PZA to the clearance of actively dividing bacilli during the first phase of treatment has not been fully explored. However, the findings from this study show that PZA has utility against fast growing bacteria and it demonstrates that the assessment of drug combinations containing PZA, used early in treatment, warrants further investigation.

\section{Ethics approval and consent to participate}

Not applicable.

\section{Consent for publication}

Not applicable.

\section{Availability of data and materials}

The datasets supporting the conclusions of this article are available in the ArrayExpress repository at https:// www.ebi.ac.uk/arrayexpress/experiments/E-MTAB-4093/

Data are also included in the Additional file 1.

\section{Additional file}

Additional file 1: Supplementary tables, S1, S2 and S3. Differentially regulated transcripts in the fast cultures during bacteriostatic and recovery phase compared to pre-PZA phase, and in the slow cultures during recovery phase compared to pre-PZA phase. (XLSX $55 \mathrm{~kb}$ )

\section{Abbreviations}

CMM Mod2: CAMR mycobacterium medium; EBA: early bactericidal activity; GTC: guanidine thiocyanate; INH: isoniazid; M. tuberculosis: Mycobacterium tuberculosis; MDR: multi-drug resistance; MGT: mean generation time; MIC: minimum inhibitory concentration; OD: optical density; POA: pyrazinoic acid; PZA: pyrazinamide; TB: tuberculosis.

\section{Competing interests}

There are no competing interest; financial or otherwise.

\section{Authors' contributions}

STP, JCA, KAH, RD, CLH-D carried out the chemostat studies. STP, RD, \& REJ carried out the microarray, statistical analyses, and data submission. JB conceived of the study and STP, JB, JCA, \& PDM participated in its design. STP, REJ, PDM, \& JB contributed to the writing of the manuscript and all authors approved the final version

\section{Acknowledgements}

The authors would like to dedicate this paper to the memory of Kim Hatch, who made a substantial contribution to the chemostat studies described here, but sadly she passed away before this work could be published.

\section{Funding}

Funding was received from Department of Health Grant in Aid and the National Institute of Health Research. The views expressed in this publication are those of the authors and not necessarily those of Public Health England, the National Institute for Health Research, or the Department of Health. The research leading to these results also received funding from the Innovative Medicines Initiative Joint Undertaking under grant agreement $n^{\circ} 115337$, resources of which are composed of financial contribution from the European Union's Seventh Framework Programme (FP7/2007-2013) and EFPIA companies' in kind contribution.

\section{Author details}

${ }^{1}$ Public Health England, National Infection Service, Porton Down, Salisbury, Wiltshire SP4 0JG, UK. ${ }^{2}$ School of Biological Sciences, University of East Anglia, Norwich Research Park NR4 7TJ, UK.

Received: 8 December 2015 Accepted: 29 April 2016

Published online: 17 May 2016

\section{References}

1. Short-course chemotherapy in pulmonary tuberculosis. A controlled trial by the British Thoracic and Tuberculosis Association. Lancet (London, England). 1976;2:1102-4.

2. Mitchison DA. The action of antituberculosis drugs in short-course chemotherapy. Tubercle. 1985;66:219-25.

3. Zhang $Y$, Mitchison D. The curious characteristics of pyrazinamide: a review. Int J Tuberc Lung Dis. 2003;7:6-21.

4. Peterson ND, Rosen BC, Dillon NA, Baughn AD. Uncoupling environmental $\mathrm{pH}$ and intrabacterial acidification from pyrazinamide susceptibility in Mycobacterium tuberculosis. Antimicrob Agents Chemother. 2015;59:7320-6.

5. Zhang Y, Permar S, Sun Z. Conditions that may affect the results of susceptibility testing of Mycobacterium tuberculosis to pyrazinamide. J Med Microbiol. 2002:51:42-9. 
6. Hu Y, Coates AR, Mitchison DA. Sterilising action of pyrazinamide in models of dormant and rifampicin-tolerant Mycobacterium tuberculosis. Int I Tuberc Lung Dis. 2006;10:317-22.

7. Beste DJV, Espasa M, Bonde B, Kierzek AM, Stewart GR, McFadden J. The genetic requirements for fast and slow growth in mycobacteria. PLoS One. 2009:4:e5349.

8. Jeeves RE, Marriott AAN, Pullan ST, Hatch KA, Allnutt JC, Freire-Martin I, Hendon-Dunn CL, Watson R, Witney AA, Tyler RH, Arnold C, Marsh PD, McHugh TD, Bacon J. Mycobacterium tuberculosis is resistant to isoniazid at a slow growth rate by single nucleotide polymorphisms in kat $\mathrm{G}$ codon Ser315. Plos One. 2015;10:e0138253.

9. Lanoix J-P, loerger T, Ormond A, Kaya F, Sacchettini J, Dartois V, Nuermberger E. Selective inactivity of pyrazinamide against tuberculosis in $\mathrm{C} 3 \mathrm{HeB} / \mathrm{FeJ}$ mice is best explained by neutral $\mathrm{pH}$ of caseum. Antimicrob Agents Chemother. 2015:60(2):735-43.

10. Gumbo T, Dona CSWS, Meek C, Leff R. Pharmacokinetics-pharmacodynamics of pyrazinamide in a novel in vitro model of tuberculosis for sterilizing effect: a paradigm for faster assessment of new antituberculosis drugs. Antimicrob Agents Chemother. 2009:53:3197-204.

11. Jenkins C, Bacon J, Allnutt J, Hatch KA, Bose A, O'Sullivan DM, Arnold C, Gillespie SH, McHugh TD. Enhanced heterogeneity of rpoB in Mycobacterium tuberculosis found at low pH. J Antimicrob Chemother 2009;63:1118-20.

12. Bacon J, James BW, Wernisch L, Williams A, Morley KA, Hatch GJ, Mangan JA, Hinds J, Stoker NG, Butcher PD, Marsh PD. The influence of reduced oxygen availability on pathogenicity and gene expression in Mycobacterium tuberculosis. Tuberculosis (Edinb). 2004;84:205-17.

13. Bacon J, Dover LG, Hatch KA, Zhang Y, Gomes JM, Kendall S, Wernisch L, Stoker NG, Butcher PD, Besra GS, Marsh PD. Lipid composition and transcriptional response of Mycobacterium tuberculosis grown under ironlimitation in continuous culture: identification of a novel wax ester. Microbiology. 2007;153(Pt 5):1435-44.

14. James BW, Williams A, Marsh PD. The physiology and pathogenicity of Mycobacterium tuberculosis grown under controlled conditions in a defined medium. J Appl Microbiol. 2000;88:669-77.

15. Kolesnikov $\mathrm{N}$ et al. ArrayExpress update-simplifying data submissions. Nucleic Acids Res. 2015. doi:10.1093/nar/gku1057. Accessed 21 Apr 2016.

16. Zhang $Y$, Wade MM, Scorpio A, Zhang H, Sun Z. Mode of action of pyrazinamide: disruption of Mycobacterium tuberculosis membrane transport and energetics by pyrazinoic acid. J Antimicrob Chemother. 2003;52:790-5.

17. Scorpio A, Zhang Y. Mutations in pncA, a gene encoding pyrazinamidase/ nicotinamidase, cause resistance to the antituberculous drug pyrazinamide in tubercle bacillus. Nat Med. 1996;2:662-7.

18. Lu P, Haagsma AC, Pham H, Maaskant JJ, Mol S, Lill H, Bald D. Pyrazinoic acid decreases the proton motive force, respiratory ATP synthesis activity, and cellular ATP levels. Antimicrob Agents Chemother. 2011;55:5354-7.

19. Wade MM, Zhang Y. Effects of weak acids, UV and proton motive force inhibitors on pyrazinamide activity against Mycobacterium tuberculosis in vitro. J Antimicrob Chemother. 2006;58:936-41.

20. Zhang Y, Shi W, Zhang W, Mitchison D. Mechanisms of pyrazinamide action and resistance. Microbiol Spectr. 2014;2:MGM2-0023-2013.

21. Harrison RA. Acid-base balance. Respir Care Clin N Am. 1995;1:7-21.

22. Jindani A, Doré CJ, Mitchison DA. Bactericidal and sterilizing activities of antituberculosis drugs during the first 14 days. Am J Respir Crit Care Med. 2003:167:1348-54

23. Grosset J, Truffot C, Fermanian J, Lecoeur H. Sterilizing activity of the main drugs on the mouse experimental tuberculosis (author's transl). Pathol Biol (Paris). 1982;30:444-8.

24. Controlled trial of 2, 4, and 6 months of pyrazinamide in 6-month, threetimes-weekly regimens for smear-positive pulmonary tuberculosis, including an assessment of a combined preparation of isoniazid, rifampin, and pyrazinamide. Results at 30 months. Hon. Am Rev Respir Dis 1991;143(4 Pt 1):700-6.

25. Ellard GA. Absorption, metabolism and excretion of pyrazinamide in man. Tubercle. 1969;50:144-58

26. Grosset J, Almeida D, Converse PJ, Tyagi S, Li S-Y, Ammerman NC, Pym AS, Wallengren K, Hafner R, Lalloo U, Swindells S, Bishai WR. Modeling early bactericidal activity in murine tuberculosis provides insights into the activity of isoniazid and pyrazinamide. Proc Natl Acad Sci U S A. 2012;109:15001-5.

27. Dawson $\mathrm{R}$, Diacon AH, Everitt D, van Niekerk C, Donald PR, Burger DA, Schall $R$ Spigelman M, Conradie A, Eisenach K, Venter A, Ive P, Page-Shipp L, Variava E,
Reither K, Ntinginya NE, Pym A, von Groote-Bidlingmaier F, Mendel CM. Efficiency and safety of the combination of moxifloxacin, pretomanid (PA-824), and pyrazinamide during the first 8 weeks of antituberculosis treatment: a phase $2 b$, open-label, partly randomised trial in patients with drug-susceptible or drug-resistant pul. Lancet (London, England). 2015;385:1738-47.

28. Huang DW, Sherman BT, Lempicki RA. Systematic and integrative analysis of large gene lists using DAVID bioinformatics resources. Nat Protoc. 2009;4: 44-57.

29. Ashburner M, Ball CA, Blake JA, Botstein D, Butler H, Cherry JM, Davis AP, Dolinski K, Dwight SS, Eppig JT, Harris MA, Hill DP, Issel-Tarver L, Kasarskis A, Lewis S, Matese JC, Richardson JE, Ringwald M, Rubin GM, Sherlock G. Gene ontology: tool for the unification of biology. The Gene Ontology Consortium. Nat Genet. 2000;25:25-9.

30. Wu CH, Huang H, Arminski L, Castro-Alvear J, Chen Y, Hu Z-Z, Ledley RS, Lewis KC, Mewes H-W, Orcutt BC, Suzek BE, Tsugita A, Vinayaka CR, Yeh L-SL, Zhang J, Barker WC. The Protein Information Resource: an integrated public resource of functional annotation of proteins. Nucleic Acids Res. 2002;30:35-7.

31. Kanehisa M, Goto S. KEGG: kyoto encyclopedia of genes and genomes. Nucleic Acids Res. 2000;28:27-30.

32. Shi W, Zhang $X$, Jiang $X$, Yuan $H$, Lee JS, Barry CE, Wang $H$, Zhang W, Zhang Y. Pyrazinamide inhibits trans-translation in Mycobacterium tuberculosis. Science. 2011;333:1630-2.

33. Tan $Y$, Hu Z, Zhang T, Cai X, Kuang H, Liu Y, Chen J, Yang F, Zhang $K$, Tan S, Zhao $Y$. Role of pncA and rpsA gene sequencing in detection of pyrazinamide resistance in Mycobacterium tuberculosis isolates from southern China. J Clin Microbiol. 2014;52:291-7.

34. Miotto $P$, Cabibbe AM, Feuerriegel S, Casali N, Drobniewski F, Rodionova $Y$, Bakonyte D, Stakenas P, Pimkina E, Augustynowicz-Kopeć E, Degano M, Ambrosi A, Hoffner S, Mansjö M, Werngren J, Rüsch-Gerdes S, Niemann S, Cirillo DM. Mycobacterium tuberculosis pyrazinamide resistance determinants: a multicenter study. MBio. 2014;5:e01819-14.

35. Xia Q, Zhao L-L, Li F, Fan Y-M, Chen Y-Y, Wu B-B, Liu Z-W, Pan A-Z, Zhu M. Phenotypic and genotypic characterization of pyrazinamide resistance among multidrug-resistant Mycobacterium tuberculosis isolates in Zhejiang, China. Antimicrob Agents Chemother. 2015;59:1690-5.

36. Keiler KC. Biology of trans-translation. Annu Rev Microbiol. 2008:62:133-51.

37. Rodionova IA, Schuster BM, Guinn KM, Sorci L, Scott DA, Li X, Kheterpal I, Shoen C, Cynamon M, Locher C, Rubin EJ, Osterman AL. Metabolic and bactericidal effects of targeted suppression of NadD and NadE enzymes in mycobacteria. MBio. 2014;5.

38. Cook GM, Greening C, Hards K, Berney M. Energetics of pathogenic bacteria and opportunities for drug development. Adv Microb Physiol. 2014;65:1-62.

39. Li J, Ji L, Shi W, Xie J, Zhang Y. Trans-translation mediates tolerance to multiple antibiotics and stresses in Escherichia coli. J Antimicrob Chemother. 2013;68:2477-81.

40. Shi W, Chen J, Feng J, Cui P, Zhang S, Weng X, Zhang W, Zhang Y. Aspartate decarboxylase (PanD) as a new target of pyrazinamide in Mycobacterium tuberculosis. Emerg Microbes Infect. 2014;3:e58.

\section{Submit your next manuscript to BioMed Central and we will help you at every step:}

- We accept pre-submission inquiries

- Our selector tool helps you to find the most relevant journal

- We provide round the clock customer support

- Convenient online submission

- Thorough peer review

- Inclusion in PubMed and all major indexing services

- Maximum visibility for your research

Submit your manuscript at www.biomedcentral.com/submit 